\title{
ARTICULAÇÃO ENTRE ENSINO, PESQUISA E EXTENSÃO: CONTRIBUIÇÕES DO PROGRAMA DE EDUCAÇÃO TUTORIAL (PET) PARA A FORMAÇÃO DE GRADUANDOS EM BIOLOGIA
}

\author{
FEITOSA, Raphael Alves (Brasil, Ceará, Fortaleza) ${ }^{1 *}$ \\ DIAS, Ana Maria lorio (Brasil, Ceará, Fortaleza) ${ }^{1 *}$ \\ ${ }^{1}$ Universidade Federal do Ceará \\ ORCID ID: https://orcid.org/0000-0003-3008-3508* \\ ORCID ID: https://orcid.org/0000-0001-8896-6966
}

\begin{abstract}
RESUMO
Este trabalho utiliza a perspectiva das Associações de Companheiros de Ofício aplicada à formação profissional específica e docente para investigar as contribuições do Programa de Educação Tutorial para uma concepção articulada entre teoria e prática na área de Biologia. Através de um estudo de caso, com integrantes de um grupo do Programa de Educação Tutorial de uma universidade federal nordestina, no qual se utiliza análise de documentos e entrevistas, notou-se que os partícipes percebem que as ações desenvolvidas de forma articulada são importantes para sua formação como futuros docentes de Biologia. Tais ações buscam, de forma precária, integrar ensino, pesquisa e extensão, característica dessa política pública; além disso, carecem de articulação com a formação docente, seja para a Educação Básica, seja para a Educação Superior.
\end{abstract}

\section{PALAVRAS-CHAVE}

Formação de professores. Políticas públicas. Educação Superior.

\section{ARTICULATION BETWEEN TEACHING, RESEARCH AND EXTENSION: \\ TUTORIAL EDUCATION PROGRAM (PET) CONTRIBUTIONS FOR BIOLOGY STUDENTS}

\begin{abstract}
This paper uses the prospect of Association of Craft Fellow applied to teacher training to investigate Tutorial Education Program contributions for Biology studants and teachers education. Through a Case Study with members of a group from the Tutorial Education Program at a Brazilian Federal Northeastern university, which uses document analysis and interviews, it was noted that the partaker realize that the actions developed by the group are relevant to their training as future teachers of Biology. Such actions articulated, precariously, through the principle of acting in teaching, research and extension, characteristic of this public policy; besides that, they needs articulation with teacher education, either for Basic Education or for Higher Education.
\end{abstract}

\section{KEYWORDS}

Academic education of teachers. Public policy. Higher education.

Educação \& Formação, Fortaleza, v. 4, n. 12, p. 169-190 set./out. 2019 


\title{
ARTICULACIÓN ENTRE ENSINO, INVESTIGACIÓN Y EXTENSIÓN: CONTRIBUCIONES DEL PROGRAMA DE EDUCACIÓN TUTORIAL (PET) PARA LA FORMACIÓN DE GRADUANDOS EN BIOLOGÍA
}

\begin{abstract}
RESUMEN
Este trabajo utiliza la perspectiva de las Asociaciones de Compañeros de Oficio aplicada a la formación profesional específica y docente para investigar las contribuciones del Programa de Educación Tutorial para una concepción articulada entre teoría y práctica en el área de Biología. A través de un estudio de caso con integrantes de un grupo del Programa de Educación Tutorial de una universidad federal nordestina, en el que se utiliza análisis de documentos y entrevistas, se notó que los partícipes perciben que las acciones desarrolladas de forma articulada son importantes para su formación como futuros docentes de Biología. Tales acciones, de forma precaria, buscan integrar enseñanza, investigación y extensión, característica de esa política pública; además, carecen de articulación con la formación docente, sea para la Educación Básica, sea para la Educación Superior.
\end{abstract}

\section{PALABRAS CLAVE}

Formación de profesores. Políticas públicas. Educación universitaria.

\section{INTRODUÇÃo}

Políticas públicas voltadas ao campo da formação profissional são alvos de investigações científicas no Brasil (FRIGOTTO; CIAVATTA; RAMOS, 2005), indicando a relevância da temática, com vistas à articulação entre formação básica e uma inserção profissional cidadã. Na maioria das vezes, no entanto, evidenciamos programas focais e contingentes, num percurso caracterizado por intensas contradições. O que caracteriza os programas de formação profissional "[...] é a falta de integração com outras políticas, [...]" (FRIGOTTO; CIAVATTA; RAMOS, 2005, p. 1106). Assim, podemos dizer que as políticas voltadas para a Educação, mais especificamente para a formação básica profissional, são insuficientes em sua efetiva implementação, na articulação com as ações de fomento (inclusive para o desenvolvimento de pesquisas e estudos sobre políticas e estratégias para um melhor desenvolvimento dessa modalidade de Educação), nos diferentes níveis de governo, em consonância com o Plano Nacional de Educação (PNE). Diante desse quadro, compreende-se ser relevante analisar o desenvolvimento de políticas públicas formativas. Neste artigo, delimitaremos nossas reflexões à formação profissional inicial nas universidades. 
Um dos programas existentes em diversos cursos de graduação é o Programa de Educação Tutorial (PET), oficialmente instituído pelo Governo Federal através da Lei n. 11.180/2005, em substituição ao outrora denominado Programa Especial de Treinamento, criado e implantado em 1979 pela Coordenação de Aperfeiçoamento de Pessoal de Nível Superior (Capes).

Atualmente o PET é gerenciado pela Secretaria de Educação Superior (SESu), vinculada ao Ministério da Educação (MEC), funcionando como um programa acadêmico direcionado a alunos regularmente matriculados em cursos de graduação, orientados por um tutor, para desenvolverem atividades norteadas pelo princípio da indissociabilidade entre ensino, pesquisa e extensão (BRASIL, 2005).

Coligando-se a tal princípio orientador, o programa aponta como objetivo geral promover a formação "[...] ampla e de qualidade acadêmica dos alunos de graduação envolvidos direta ou indiretamente com o programa, estimulando a fixação de valores que reforcem a cidadania e consciência social" de seus partícipes, além de contribuir para a melhoria dos cursos de graduação (BRASIL, 2005, p. 7).

Assim, fazem parte dos grupos PET, além dos alunos de graduação, os professores tutores, docentes das Instituições de Ensino Superior, que são responsáveis por orientar a manutenção das atividades do programa (BRASIL, 2005). Segundo consta nos documentos oficiais, o PET conta com 842 grupos distribuídos entre 121 Instituições de Educação Superior (BRASIL, 2016) ${ }^{1}$.

Merecem destaque os aspectos acadêmicos e políticos da atuação dos integrantes desse programa. A esse respeito, analisamos os cinco últimos anais dos Encontros Nacionais de Grupos PET (ENAPET, 2014, 2015, 2016, 2017, 2018). Nesses eventos, os integrantes do programa de todo o país apresentaram os trabalhos que desenvolveram junto aos seus grupos, traçaram discussões acerca de aspectos formativos, fizeram reivindicações e elaboraram planos de atuação conjuntos para os anos subsequentes.

No Enapet de 2014, apresentaram-se 453 trabalhos de pesquisa sobre diferentes temáticas, dos quais apenas 38 se referiam aos aspectos relativos ao ensino: aprendizagem, avaliação, didática, elaboração de materiais educativos/didáticos, uso de tecnologias digitais de informação e comunicação. No Enapet de 2015, o número cresce

${ }^{1}$ Conferir em: <http://portal.mec.gov.br/pet>. Acesso em: 21 fev. 2019.

Educação \& Formação, Fortaleza, v. 4, n. 12, p. 169-190 set./out. 2019

DOI: https://doi.org/10.25053/redufor.v4i12.819

http://seer.uece.br/redufor 
para 465 trabalhos apresentados, dos quais 61 abordaram esses temas relativos ao ensino. No ano de 2016, tivemos no Enapet 199 trabalhos nas diferentes áreas, dos quais 32 tratavam de temas relativos ao ensino. Em 2017, foram 300 trabalhos, sendo 44 referentes a temáticas educativas/educacionais. Em 2018, por sua vez, tivemos 487 trabalhos, com 68 voltados para o ensino.

$\mathrm{Na}$ área de Biologia, que nos interessou mais diretamente para efeitos da elaboração deste artigo, encontramos as seguintes informações: no Enapet de 2014, de 15 trabalhos, somente dois versavam sobre ensino; no Enapet de 2015, foram aprovados 19 trabalhos na área de Biologia, dos quais apenas três abordavam aspectos pertinentes ao ensino. Em 2016, havia quatro referentes ao ensino, dentre cinco. No ano de 2017, dentre 11 trabalhos apresentados, tivemos quatro voltados à temática do ensino. Em 2018, foram 26 trabalhos na área de Biologia, dos quais sete relativos ao ensino.

Em todos os encontros, verificamos diversos trabalhos que versavam sobre acolhida de alunos novatos - estes não foram considerados, uma vez que, em nossa análise, não se relacionavam diretamente com o ensino. Além disso, em várias áreas, encontramos pelo menos um trabalho em cada área com a temática e/ou título indicando a indissociabilidade entre ensino, pesquisa e extensão em determinado(s) grupo(s) PET - o que reforça a legitimação do tema pela comunidade petiana.

É relevante salientar que alguns trabalhos acadêmicos também já analisaram contribuições que o PET trouxe para a formação profissional de seus integrantes. $\mathrm{Na}$ área de Enfermagem, encontram-se, por exemplo, as pesquisas de Cassiani, Ricci e Souza (1998) e de Petrilli-Filho e Martins (2001). As autoras do primeiro analisaram as representações dos bolsistas acerca das contribuições do programa. Dentre os resultados apresentados, os integrantes foram uníssonos ao indicar que o PET havia cooperado para seu desenvolvimento pessoal e profissional através da promoção de ações que levam à integração da formação acadêmica e da futura atividade profissional (CASSIANI; RICCI; SOUZA, 1998).

Já o estudo de Petrilli-Filho e Martins (2001, p. 92-93) indica que o programa parece ser importante na formação do profissional do(a) enfermeiro(a), visto que ele busca: 
[...] oferecer uma formação acadêmica de excelente nível aos alunos de graduação; incentivar o ingresso na pós-graduação; estimular a melhoria da qualidade de ensino de graduação através do desenvolvimento de novas práticas e experiências pedagógicas; multiplicar as atividades desenvolvidas pelos bolsistas sobre o conjunto de alunos do curso e a interação dos alunos do programa com o corpo docente e discente da instituição.

Para Câmara, Grosseman e Pinho (2015, p. 826), o estudo que fizeram permitiu identificar:

[...] elementos importantes de inovação educacional apontados na literatura, e nos permite considerar a proposta de EIP do PET-Saúde como inovação educacional exitosa. O desenvolvimento do projeto [...] envolveu um conjunto de intervenções, processos e decisões que buscaram modificar atitudes, ideias, culturas, modelos e práticas pedagógicas. A motivação e compromisso dos docentes foram características importantes, assim como o protagonismo, compreendido como a participação dos docentes, estudantes e profissionais nas decisões pedagógicas, e a valorização da produção pessoal, original e criativa, estimulando processos intelectuais mais complexos e não repetitivos.

Ainda na área de Saúde, Caldas e colaboradores (2012, p. 33) verificaram que as ações desenvolvidas por um dos grupos PET "[...] favoreceu o ensino-aprendizagem de bolsistas e voluntários; a interdisciplinaridade; e a integração ensino, pesquisa e extensão". Essa visão otimista em relação ao Programa PET é compartilhada por Farias-Santos e Noro (2017, p. 1002), ao afirmarem que:

O estudo revelou que, na perspectiva do Enade, o PET-Saúde tem contribuído na formação dos alunos de graduação em Odontologia, Medicina e Enfermagem, considerando o melhor desempenho dos alunos em todas as provas analisadas (desempenho global, formação geral, conhecimentos específicos e saúde coletiva).

Também em outro campo profissional, o de Biblioteconomia, o mesmo programa parece ser relevante para a formação através da pesquisa acadêmica para os seus integrantes. Em investigação realizada por Ferreira (2011, p. 107), destaca-se que "[...] os esforços de integrar o curso a partir dos projetos de pesquisa e extensão do PET têm resultado na ampliação do volume de pesquisas realizadas pelo curso".

De acordo com Balau-Roque (2012, p. 101), em estudo realizado com grupos PET de todo o Brasil: 
Os resultados encontrados permitiram notar que os participantes deram ênfase às mudanças positivas proporcionadas pela vivência no PET. Essas evidências apontam para os inúmeros benefícios gerados pelo Programa e indicam a importância de sua continuidade e, inclusive, da necessidade de constante expansão, principalmente para outros estados, visto que os principais grupos estão concentrados no Sudeste.

Ademais, encontram-se relatos dessa natureza na área de Geografia, como mostram Gomes, Hauresko e Bortoli (2008), ao destacarem que as ações do PET servem como mote gerador de uma articulação entre teoria e prática profissional, evitando uma visão dicotômica que tende a segregar tais visões de mundo.

Já no campo das Ciências da Natureza, encontra-se o trabalho de Feitosa, Leite e Freitas (2011), no qual os autores descrevem e analisam atividade desenvolvida por um grupo PET, vinculada ao incentivo à reativação de laboratórios de aulas práticas de Ciências em escolas públicas de Fortaleza.

Analisando as pesquisas acima citadas, percebe-se que o PET, como política de formação profissional, vem sendo campo fértil para investigações. Contudo, ainda são escassos os trabalhos dentro do campo da formação profissional em Biologia, sejam direcionados à formação de bacharéis, sejam relativos à formação docente.

Diante das possibilidades formativas do Programa de Educação Tutorial ligadas ao desenvolvimento profissional dos estudantes de graduação, indaga-se: como os integrantes do grupo PET-Biologia da Universidade Federal do Ceará (UFC) percebem as experiências formativas vivenciadas no grupo, constituídos por formandos em bacharelado e em licenciatura? Este artigo busca responder a esse questionamento.

Ressalte-se que o PET-Biologia possui integrantes de ambas as modalidades do curso de Ciências Biológicas - bacharelado e licenciatura. Sendo assim, o objetivo desta pesquisa é analisar as percepções dos integrantes do grupo PET, aqui chamados de "petianos", a respeito das contribuições das ações desenvolvidas pelo PET-Biologia para formação, como biólogos ou licenciados, de seus integrantes, graduandos do curso de Ciências Biológicas da UFC. Espera-se, com esta investigação, contribuir para a compreensão desse programa, que tem uma conotação de política pública federal, através de um estudo de caso com foco local.

Para tanto, o presente texto está dividido da seguinte forma: inicia-se com uma breve exposição do histórico do Grupo PET-Biologia da UFC, para, em seguida, 
apresentar o referencial teórico, em que foram constituídos a pesquisa e o percurso metodológico deste estudo de caso. Por fim, os resultados da investigação são apresentados sob a forma de "Percepções sobre o PET-Biologia".

\section{UM POUCO DA HISTÓRIA DO GRUPO PET}

O grupo específico em questão é composto por tutor(a), doze bolsistas e quatro não bolsistas (PETBIOUFC, 2015) e está em atividade desde o ano de 1992. Considerando que a orientação do programa se relaciona com a interação entre ensino, pesquisa e extensão (BRASIL, 2005), arquiteta-se como indispensável analisar tais ações.

Em publicação ligada ao grupo, as atividades de ensino do grupo se vinculam a práticas de apoio ao curso de graduação, com destaque para a "[...] elaboração dos novos projetos pedagógicos de seus respectivos cursos; a promoção de cursos, oficinas, seminários didáticos e técnicos; a recepção de novos estudantes; o apoio à matrícula dos estudantes de seus respectivos cursos" (DIAS; FREITAS, 2006, p. 1).

Outrossim, também encontra-se em Dias e Freitas (2006, p. 2) a descrição das ações na área de extensão que o grupo realizou ao longo do tempo, seja com a comunidade acadêmica, "[...] com a comunidade externa à UFC, [...] com escolas de ensino fundamental e médio (feiras de profissões, oficinas, etc.)". Denota-se que as "feiras de profissões" são eventos em que são apresentados à comunidade da cidade de Fortaleza-Brasil apenas os cursos de graduação ligados aos programas PET.

Igualmente as autoras supracitadas advogam que os integrantes do grupo desenvolvem atividades de investigação, de forma individual ou coletiva, ligadas a laboratórios de pesquisa dentro dos muros da universidade. Essa conotação também parece ocorrer em grupos PET de outras áreas, como mostram os trabalhos apresentados nos Enapet $(2014,2015)$, nas publicações de Gomes, Hauresko e Bortoli (2008) e de Ferreira (2011). Segundo o que se encontra nessa literatura acadêmica, tais atividades de iniciação à pesquisa constituem ações formativas para os futuros profissionais dessas áreas.

Também desperta a atenção que, além dessas atividades, os petianos realizam ações de caráter político, como destacado por Dias e Freitas (2006), ao relatarem os 
encontros InterPET, isto é, uma série de reuniões permanentes e sistemáticas de encontros entre os grupos PET do estado do Ceará. Isso foi evidenciado nos anais dos Enapet $(2014,2015,2016,2017)$, nos quais se inserem várias reivindicações e sugestões de modificação em regimentos e outros documentos relativos à estrutura, composição, avaliação do PET, em forma de "cartas", que são enviadas à Secretaria de Educação Superior (SESu)/MEC.

Apesar dessas informações, acredita-se também ser preciso adentrar nas esferas dos estudos e das práticas curriculares para compreender as reais contribuições do programa para a formação dos futuros professores e biólogos que o integram. É o que se discutirá a seguir.

\section{TEORIAS QUE REFERENCIAM O TRABALHO}

Considerando o funcionamento dos grupos PET, decidiu-se analisar suas ações tendo como base a perspectiva da formação reflexiva de profissionais (SCHÖN, 2000), com foco na ideia de Associação de Companheiros de Ofício, isto é, "[...] num espaço-tempo marcado, preponderantemente, por uma inter-relação coletiva entre os sujeitos participantes" de determinado grupo (FEITOSA; LEITE, 2012, p. 40).

Nessa visão, dentro de um processo que privilegia a ação-reflexão cotidiana com seus companheiros, o educador elabora uma nova realidade, experimentando, arquitetando e reconstruindo através do diálogo que estabelece com seu contexto. Feitosa e Leite (2012) e Queiroz (2001) acrescentam que esse tema é uma leitura crítica das corporações medievais de ofícios aplicada à formação docente. A teoria da Associação de Companheiros de Ofício supõe a existência de diferentes níveis de saberes teóricos e práticos entre os companheiros da associação. Os mais experientes possuem uma série de saberes que são construídos na prática cotidiana, denominados de saberes da experiência, ao passo que os noviços estão em busca do desenvolvimento desses saberes.

A formação profissional, seja específica ou docente, costuma dissociar a teoria da prática. Buscou-se uma formação que rompa com esse modelo dissociativo, como mostra Eisner (2008, p. 9), o que ele denomina de campo da "arte", no qual a prática se consolida junto com a teoria, uma influenciando a outra: 
Pelo termo artista [...] não queremos dizer necessariamente pintores, dançarinos, poetas ou autores dramáticos. Nós queremos dizer indivíduos que desenvolveram as ideias, as sensações, as habilidades e a imaginação para criar um trabalho que está bem proporcionado, habilmente executado e imaginativo, que é independente do domínio em que um indivíduo trabalha. O maior elogio que podemos dar a alguém é dizer que ele ou ela é um artista, seja como carpinteiro, cirurgião, cozinheiro, engenheiro, físico ou professor [...].

Os currículos de formação, via de regra, não abordam situações que surgem durante a prática profissional e que geram incertezas, singularidades e conflitos (SCHÖN, 2000). Daí a necessidade de esses currículos serem (re)dimensionados, articulando o ensino com pesquisa, prática, teoria, reflexão - considerando o formando como sujeito hermenêutico (produtor de significados) e epistêmico (produtor de saberes e conhecimentos para si e para outros), dimensões relevantes e "[...] inerentes à reflexividade crítica do sujeito pesquisador" (THERRIEN, 2011, p. 52). Dito de forma mais específica, busca-se compreender a importância de uma formação baseada em um ensino reflexivo.

Nessa linha de pensamento, Feitosa e Leite (2012) supõem que também a formação de professores pode operar sob esse ponto de vista articulador e colaborativo. Em seus trabalhos, esses autores apresentam evidências de que é possível conjecturar o trabalho docente como uma espécie de educação artística, feita dentro de corporações de aprendizes ensinantes, ou seja, de grupos formativos, com base nas categorias como aspectos fundantes das Associações de Companheiros de Ofício: engajamento; busca por uma transformação social; trabalho interdisciplinar; professor artista; colaboração; reflexão individual e coletiva, como se verá mais detalhadamente a seguir.

\section{PERCURSO METODOLÓGICO}

A presente investigação toma como metodologia de base o estudo de caso, com foco qualitativo (YIN, 2005). O estudo de caso é uma estratégia que é bastante utilizada ao se examinar acontecimentos contemporâneos (STAKE, 1995; YIN, 2005). Esses autores indicam que os estudos de caso têm um amplo histórico na área de Saúde e no Serviço Social, sendo que, no início de sua aplicação nesses campos, eles tinham como 
finalidade o estudo clínico, isto é, diagnosticar um problema apresentado por um paciente, bem como seguir sua indicação clínico-terapêutica.

Tal metodologia passou a ser aplicada, desde os anos de 1960/1970, no campo da educação, entretanto aparece com um sentido restrito, isto é, descrever uma unidade educacional, seja ela uma escola, um docente, um grupo de discentes, uma sala de aula. Para Stake (1995), tal compreensão gerou alguns equívocos de interpretação dentro do campo, além do nascimento de pesquisas com aspectos pontuais e análises pouco profundas. Com o desenvolvimento e ampliação das abordagens qualitativas de pesquisa, na década de 1980, é que os estudos de caso ressurgem na pesquisa em Educação com um sentido mais amplo, ou seja, enfocar um fenômeno particular, considerando suas múltiplas dimensões e seu contexto histórico.

Yin (2005, p. 32) afirma que um estudo de caso "[...] investiga um fenômeno contemporâneo dentro de seu contexto da vida real, especialmente quando os limites entre o fenômeno e o contexto não estão claramente definidos", haja vista que o estudo de caso enfrenta uma situação tecnicamente única, em que haverá mais variáveis de interesse do que alvos de dados. Comumente os pesquisadores utilizam diversas ferramentas de coleta de dados nos estudos de caso.

$\mathrm{Na}$ presente investigação, utilizou-se a análise de documentos e entrevistas como fontes primárias de informação. Iniciou-se este percurso com uma análise documental sobre a legislação relacionada ao PET (BRASIL, 2005). Posteriormente investigou-se o projeto pedagógico do curso de licenciatura em Ciências Biológicas (UFC, 2005), visando à compreensão da organização do currículo formal do curso, tentando apreender como o programa se relaciona com o projeto. Por fim, as informações a respeito do grupo em análise foram coletadas por meio de canal eletrônico divulgado em rede social (PETBIOUFC, 2015).

Outrossim, também foram realizadas entrevistas com bolsistas, ex-bolsistas e duas professoras, sendo uma tutora do PET e outra participante do programa, indicado por ela, da modalidade de licenciatura do curso em questão.

Os alunos em formação aqui entrevistados, em número de três (dos 12 participantes do programa), foram identificados com nomes fictícios de pedras preciosas, a saber: Rubi, Safira e Ametista. Com essa designação, traz-se à tona a metáfora de que os partícipes desta pesquisa constituíram verdadeiras joias, descobertas e aprimoradas por 
trabalho "artístico" em atelier formador. Esses alunos foram selecionados como representantes de períodos de formação: um dentre os discentes que estavam entre o segundo e o quarto período do curso de graduação; um representando os estudantes do quinto e sexto período; e um dentre os universitário do sétimo e oitavo período do curso, dentre os participantes do PET-Biologia; esses alunos foram, então, após a classificação por períodos, escolhidos por sorteio dentre os que aceitaram participar da entrevista.

Igualmente também foram entrevistados três graduados no curso de Ciências Biológicas, da modalidade de licenciatura, que haviam sido integrantes do PET-Biologia durante sua graduação. A seleção se deu em função das respostas obtidas ao "chamamento"/convite enviado por e-mail aos 12 mais recentes graduados participantes. Nesse processo, buscou-se encontrar as percepções desses ex-petianos sobre as contribuições do programa para a sua formação profissional inicial. Esses entrevistados foram denominados de Diamante, Quartzo e Topázio.

A atual tutora do PET-Biologia, aqui chamada de Ágata, também foi entrevistada, assim como 0 foi a docente por ela indicada para esta pesquisa, atuante na modalidade licenciatura, denominada de Jade.

Vale ressaltar que a realização dessa fase de entrevistas, ainda que não tenha sido formalizada a solicitação ao Conselho de Ética da Instituição de Ensino Superior, somente foi feita após aprovação e consentimento dos entrevistados, registrados através de um termo de consentimento livre e esclarecido, que continha os informes e o detalhamento sobre a presente investigação ${ }^{2}$, conforme sugerido por Stake (1995) e por Yin (2005). Ainda como parte integrante da preocupação com os aspectos éticos da pesquisa, as entrevistas foram transcritas e, em seguida, o material foi enviado por correio eletrônico para a análise do(a) entrevistado(a), que pôde fazer modificações que julgasse necessárias no texto transcrito. As alterações e/ou sugestões dos entrevistados foram acrescentadas aos dados da pesquisa. Após essa etapa, novamente 0 entrevistado pôde aprovar ou não sua participação na pesquisa.

\footnotetext{
2 A esse respeito, procurou-se seguir as orientações da Resolução n. 510, de 7 de abril de 2016, que dispõe sobre as normas aplicáveis a pesquisas em Ciências Humanas e Sociais. Em seu artigo 1ํㅡ, parágrafo único, estabelece que: "Não serão registradas nem avaliadas pelo sistema CEP/Conep: [...] VII - pesquisa que objetiva o aprofundamento teórico de situações que emergem espontânea e contingencialmente na prática profissional, desde que não revelem dados que possam identificar 0 sujeito; e VIII - atividade realizada com o intuito exclusivamente de educação, ensino ou treinamento sem finalidade de pesquisa científica, de alunos de graduação, de curso técnico, ou de profissionais em especialização".
}

Educação \& Formação, Fortaleza, v. 4, n. 12, p. 169-190 set./out. 2019

DOI: https://doi.org/10.25053/redufor.v4i12.819

http://seer.uece.br/redufor 
Ao longo do presente texto, preservou-se o modo original com que os entrevistados se expressaram, buscando-se preservar a precisão e a intenção dos discursos. Foram utilizados alguns aspectos que caracterizam a análise de conteúdo, segundo Bardin (1977) e Franco (2005), para a compreensão dos achados. A análise de conteúdo considera a rigorosidade textual e a necessidade de ir além das aparências contidas nos documentos oficiais e discursos dos participantes da pesquisa. Tal análise pode ser aplicada ao que é falado ou escrito em documentos, questionários ou entrevistas, o que estiver contido em imagens de filmes, desenhos, pinturas, cartazes e outras formas de comunicação não verbal, assim como em comportamentos, gestos e posturas.

Dessa forma, expõem-se a seguir os resultados da investigação, analisando-se as percepções de seus integrantes acerca do programa e da sua formação através do PET, dando foco para as ações mais recentes do grupo.

\section{PERCEPÇÕES SOBRE O PET-BIOLOGIA}

Durante a análise dos dados coletados por meio do documento que formaliza a estrutura curricular do curso, percebe-se que a UFC (2005, p. 13) explicitamente indica que "[...] o Programa de Educação Tutorial (PET) está ligado à Pró-Reitoria de Graduação", relacionando-se com a formação profissional de seus estudantes. Nesse sentido, observa-se que esse programa pode fazer parte do percurso acadêmico apenas de alguns estudantes (aproximadamente em número máximo de 12 bolsistas, podendo ser admitida a participação de estudantes voluntários), percurso chamado de curriculum / caminho (FEITOSA; LEITE, 2012; QUEIROZ, 2001).

A matriz curricular do curso de Ciências Biológicas, na modalidade licenciatura, iniciada em 2006, também potencializa a participação de graduandos nas atividades ligadas à Educação na área de Ciências. Para a docente entrevistada:

E com relação ao currículo antigo, acho que nesse novo temos um avanço em relação à criticidade e atitude participativa dos alunos, inclusive em relação ao interesse em pesquisa em ensino (educação). A necessidade de realizar um TCC [Trabalho de Conclusão de Curso] também tem contribuído para isso. Porém, vejo que atividades que não constam no currículo formal têm contribuído muito com a formação dos biólogos docentes, como os grupos Pibid [Programa de Bolsas de

Educação \& Formação, Fortaleza, v. 4, n. 12, p. 169-190 set./out. 2019 
Iniciação à Docência] da Biologia e de Educação Ambiental, o grupo PET e o Lebio [Laboratório de Ensino de Biologia]. (JADE).

Corroborando o ponto de vista dessa professora, os licenciandos trouxeram semelhante percepção sobre o relevante papel dessas "atividades que não constam no currículo formal" na formação docente. Um dos estudantes do quarto semestre foi enfático ao escrever que, além das disciplinas cursadas, "[...] a participação de bolsas como monitoria, iniciação científica e Pibid são fundamentais na formação por aproximar a realidade fora da universidade a nós [alunos]" (RUBI). Esse mesmo pensamento parece ser, de certa forma, hegemônico entre aqueles que cursam a modalidade de bacharelado.

O tema da interdisciplinaridade também emergiu dessas declarações sobre esses projetos. Por exemplo, uma aluna comentou que ela havia participado de atividades interdisciplinares em sua formação universitária somente "[...] em projetos extra-classe (sic), como trabalhos no PET e afins" (SAFIRA).

A maioria dos licenciandos reconhece que esses programas são parte integrante das atividades curriculares das Ciências Biológicas, mas uma minoria não percebe dessa forma. Por exemplo, uma outra educanda do quinto semestre do curso afirmou que havia participado de uma atividade de caráter interdisciplinar que havia contado com o "[...] Programa de Educação Tutorial (PET) para a realização de uma atividade em um colégio público", contudo ela foi enfática ao escrever que essa atividade "[...] foi uma atividade do PET, e não do [curso de] Ciências Biológicas UFC" (AMETISTA). Percebeu-se que ela não considera que o currículo do curso de Ciências Biológicas da UFC permita a interdisciplinaridade. Para ela, esse tipo de atividade somente pode ser alçado quando se participa de outros projetos, como no caso em questão, em que vivenciou "uma atividade do PET" - com isso, o PET ganhou destaque na formação.

Solicitou-se que a tutora explicitasse sua opinião sobre as ações elaboradas no PET. Assim, Ágata iniciou sua fala informando que o grupo é formado por 12 bolsistas da graduação, alguns petianos voluntários e "[...] tem a colaboração dos alunos da Pós-Graduação em Ecologia". Tal relação foi importante na elaboração de duas atividades, a saber: a primeira é o "[...] Peteco, que é um projeto de extensão de educação ambiental"; a segunda é o "[...] curso de férias, que acontece sempre em julho, mas os bolsistas planejam durante $o$ ano inteiro" (ÁGATA).

Educação \& Formação, Fortaleza, v. 4, n. 12, p. 169-190 set./out. 2019

DOI: https://doi.org/10.25053/redufor.v4i12.819 
Segundo o que se pôde constatar, nessa entrevista, o curso de férias é uma atividade desenvolvida com alunos e professores de escolas da rede pública, que são recebidos pelos integrantes do PET nas dependências da UFC durante o período de férias escolares. Conforme relato da tutora, desde 2012 foram desenvolvidas temáticas ligadas ao campo do ambientalismo, como ecologia, educação ambiental e sustentabilidade.

Ao expor a forma como ocorre o planejamento dessa(s) atividade(s), a docente enfatizou a pesquisa e a dedicação na elaboração de material sobre o conteúdo a ser explorado com os professores e estudantes participantes, mas não mencionou, por exemplo, sobre aspectos de didática próprios da formação docente. Além dessas atividades, a entrevistada informou que, através de sua vivência com os bolsistas, ela foi capaz de perceber alguns aspectos que resultaram na melhoria da formação desses alunos participantes dos processos desenvolvidos no grupo. Segundo a tutora:

[...] o PET é interessante porque você vê a evolução do aluno. Ele entra muito quietinho, não fala nada, fica meio tímido, aí, no final do semestre, ele já está assim mais envolvido, ele já coloca as ideias dele. Então, assim, eu acho que isso é interessante. (ÁGATA).

Para a professora, ao potencializar experiências diversas, que incluem o convívio em grupo, a discussão e a colaboração, o PET permite uma "evolução do aluno", ou seja, o seu desenvolvimento como pessoa. Assim, Ágata enxerga no supracitado programa um potencial formativo interessante. Isso parece ser pertinente para a presente investigação, pois as estratégias pedagógicas desenvolvidas no grupo indicam que há espaço para o desenvolvimento de uma formação que vá além de uma mera técnica, abrindo caminho para o graduando alçar novos voos educativos, acompanhado de seus pares - o que remete à discussão sobre as Associações de Companheiros de Ofício (FEITOSA; LEITE, 2012), em que membros veteranos rememoram suas experiências, ressignificando-as juntamente com os membros novatos ou menos experientes.

Diante da fala de Ágata, percebe-se que o currículo desenvolvido no PET permite uma vivência que vai além das disciplinas constantes no currículo do curso e dos aspectos cognitivos, uma vez que permite desenvolver relações humanas como parte integrante dos processos do grupo. Essa perspectiva lembra o que foi proposto por Feitosa e Leite (2012) em sua proposta de educar através da cooperação, permitindo reflexão coletiva. Entende-se que essa proposta se torna relevante para a formação do 
graduando (licenciando ou bacharelando) da área de Ciências Naturais/Biologia; entretanto, como relatam outros autores (GOMES; HAURESKO; BORTOLI, 2008; QUEIROZ, 2001), esse ainda é um campo em que predomina a formação com ênfase no conteúdo cognitivo específico de suas respectivas subáreas.

O pensamento de Ágata se repetiu nas entrevistas que foram feitas com os alunos já formados no curso que outrora integravam o PET. Por exemplo, dois ex-petianos relataram que as atividades do grupo são complementares àquelas que são desenvolvidas nas disciplinas do currículo do curso, bem como são relevantes para a formação do professor de Biologia. Em suas palavras:

Você aprende muito, e não é só uma coisa de conteúdo, acho que é uma interação em grupo, de dinâmica de grupo, de ter noção de administração, e todo mundo acaba meio que fazendo tudo, mesmo tendo uma divisão de trabalho. E tem que ficar sempre cooperando, porque sem cooperação as coisas não funcionam. [...] E também acho que o PET me acrescentou enquanto professora. (DIAMANTE).

Eu posso dizer, com toda certeza: o PET foi uma das melhores coisas que eu tive na universidade, por causa do próprio caráter do PET, que é de ensino, pesquisa e extensão. Então, nós trabalhávamos tanto com a graduação, com ensino e com a pesquisa na graduação, como fora da universidade também. [...] O meu processo de formação como professor, por mais que ainda esteja continuando, [...] mas a base dele começou quando eu comecei a interagir bem mais com outros indivíduos; eu comecei realmente a construir o conhecimento para poder transmitir esse conhecimento. (TOPÁZIO).

Nos trechos das falas acima, pode-se notar que eles atribuem ao PET uma relevante contribuição também na sua formação profissional docente. A esse respeito, Topázio é explícito ao afirmar que "[...] o PET foi uma das melhores coisas que eu tive na universidade". Por sua vez, Diamante argumentou que o mencionado programa "[...] me acrescentou enquanto professora". Entretanto, nada foi mencionado acerca do conteúdo específico da formação docente, que inclui reflexão sistemática sobre planejamento, didática, avaliação, relacionamento professor/aluno, dentre outros. Talvez essa seja uma lacuna a ser preenchida de forma mais sistemática e consistente, pois a formação docente, à semelhança da formação de bacharéis, também tem conteúdos específicos, como evidenciam Cunha (2005) e Veiga (2009).

Destaque-se também o trabalho colaborativo do grupo de bolsistas, que, segundo os relatantes, foi relevante para a formação dessas professoras. Esses dados

Educação \& Formação, Fortaleza, v. 4, n. 12, p. 169-190 set./out. 2019

DOI: https://doi.org/10.25053/redufor.v4i12.819

http://seer.uece.br/redufor 
vão ao encontro dos pressupostos das Associações de Companheiros de Ofício (FEITOSA; LEITE, 2012) e do que propuseram Tardif e Lessard (2009) ao advogarem que o ensino e a aprendizagem exigem interação humana. Portanto, é preciso haver um processo coletivo de reflexão sobre a prática, para que possamos avançar em relação às posturas individualistas da docência.

Ainda nesse sentido formativo em grupo, o tema da interdisciplinaridade também está contemplado nas falas dos graduados. Uma delas, Quartzo, ressaltou que o PET permitiu momentos que se relacionam para além das disciplinas e das áreas isoladas. Segundo seu relato, a vivência no grupo "[...] deu muito essa coisa de interdisciplinaridade, já que a gente tinha que conviver com pessoas de todas as áreas nos encontros gerais [de grupos PET]".

Quartzo contou que esses "encontros gerais" funcionavam como atividades de relação política entre os grupos, em que eram proferidos informes, formulavam-se estratégias de ação coletiva, entre outros. Ela afirmou ainda: "[...] às vezes, a gente não falava de coisas interdisciplinares, mas ia conhecendo os projetos dos outros grupos".

Sem dúvida, o fato de existir convivência "com pessoas de todas as áreas" parece ser benéfico para a formação dos integrantes dos grupos PET. No entanto, deve-se alertar que o simples fato de se dialogar com grupos advindos de ramos diversos do conhecimento não é suficiente para enquadrar uma atividade como sendo interdisciplinar. Isso porque, como dizem Feitosa, Leite e Freitas (2011), a interdisciplinaridade, como ação humana efetiva e inter-relacionada com áreas diversas, em busca de solucionar problemas em comum, muitas vezes é confundida com a multidisciplinaridade, isto é, a simples aderência/justaposição de campos diferentes do saber que dialogam, mas sem ter uma inter-relação efetiva (FAZENDA, 2001). Assim, muitas das práticas autodenominadas por seus atores sociais de "interdisciplinares", na verdade, são uma espécie de conversa entre representantes de ramos disciplinares que palestravam sobre um tema comum.

Numa discussão sobre a proposta do PET de articular ensino, pesquisa e extensão, percebe-se uma ação ainda incipiente. Uma aluna do curso (Ametista) informou que, para ela, o programa é relevante para sua formação profissional, pois nele "[...] a gente está na prática direto", ou seja, são realizadas atividades e experiências que vão além da teoria e para além da sala de aula. Citando alguns exemplos, a aluna 
relatou que os bolsistas podem atuar "[...] como monitores, como ouvintes, como palestrantes, a gente mesmo vai dar aula, participa. Aqui não ficamos só sentados ouvindo aquela matéria do professor, a gente está na ativa" (AMETISTA).

Outra questão que se coloca é: no caso da docência, basta ter o conhecimento específico da matéria para ser um bom professor? Segundo o que aqui se expôs, a resposta é "não". É preciso, então, buscar referências teóricas e práticas sobre a docência propriamente dita, como já se explicitou anteriormente; além disso, no que se refere à preocupação desde o anúncio deste artigo, no título, evidencia-se a necessidade de aprofundamentos acerca da afirmação do paradigma de universidade (funções de ensino - pesquisa - extensão), que deve promover e produzir conhecimentos e efetivamente torná-los acessíveis aos mais variados segmentos da sociedade.

\section{CONSIDERAÇÕES FINAIS}

Analisando os achados desta investigação reflexiva, percebe-se que, quando se investe em cursos e atividades de formação, como o PET, existem diversos efeitos para a profissionalização dos formandos, incluindo-se o aprendizado em grupo, através de ações de ensino, pesquisa e extensão.

Seguindo o ponto de vista apresentado por Feitosa e Leite (2012), encontram-se algumas semelhanças entre o grupo investigado e o que os autores denominaram Associações de Companheiros de Ofício, entre as quais destacam-se: cooperação, diversidade, trabalho interdisciplinar e busca pela transformação social, apontadas pelos entrevistados como relevantes para a sua formação, seja como professores ou como biólogos. Sendo assim, evidencia-se que o grupo PET parece ser um exemplo de proposta de professores-artistas.

Para os graduados entrevistados, as atividades desenvolvidas dentro do grupo PET-Biologia foram importantes para suas carreiras, segundo os próprios relatos. Assim, acredita-se que a escolha da aplicação de recursos públicos, na forma de programas como o PET, indica a preocupação governamental com a formação profissional em nível superior. Entretanto, ressalta-se que esses projetos, apesar de serem representativos, não englobam todos os estudantes. Ademais, compreende-se que seja necessário que

Educação \& Formação, Fortaleza, v. 4, n. 12, p. 169-190 set./out. 2019 
esse programa se relacione, de uma forma mais próxima, com outras políticas de inclusão cultural/social (FRIGOTTO; CIAVATTA; RAMOS, 2005).

Os resultados encontrados vão ao encontro dos trabalhos de outros autores que indicam que as atividades feitas em grupos podem contribuir de forma positiva para a formação dos profissionais (FEITOSA; LEITE, 2012; QUEIROZ, 2001).

As ações de pesquisa e de extensão podem estar respaldadas em teorias, ainda que não explicitadas, mas é preciso mais, pois, na contemporaneidade, as rápidas transformações reservam às universidades o desafio de reunir, em ações integradas de ensino, pesquisa e extensão, para além dos conhecimentos (re)sistematizados, a superação das desigualdades sociais e regionais, com qualidade e cooperação (inter)nacional, embora não se negue a relevância. Não se trata de negar a pertinência e a relevância do ensino, da pesquisa e da extensão em si mesmos, mas compreender as atividades de ensino, extensão e pesquisa, de forma articulada, como recursos vitais aos processos de ensino e de aprendizagem. Isso requer, por sua vez, uma proposta de formação profissional fortemente integrada à vivência de situações reais numa relação dialética entre teoria e prática.

Essa perspectiva exige, além de educadores imbricados com investigação e questionamentos quanto aos rumos da sociedade e que adotam ou (re)criam novas práticas pedagógicas, um outro desenho curricular, interdisciplinar, mais permeável às transformações sociais em curso, privilegiando a articulação teoria-prática na formação integral do estudante (DIAS, 2009). O mesmo ocorre com a docência (especificamente com o ensino), que continua sendo realizada de forma mais intuitiva do que científica. No caso da formação docente, entretanto, urge um envolvimento maior com a profissão e seus aspectos técnicos, didáticos, científicos, pois, à semelhança de qualquer outra profissão, a docência requer conhecimentos específicos (e isso ainda precisa ser trabalhado nos grupos PET).

Não há formação específica para a docência para a Educação Superior: a própria Lei n. 9.394/1996, Lei de Diretrizes e Bases da Educação Nacional (LDBEN), no artigo 66, indica que "A preparação para o exercício do magistério superior far-se-á em nível de pós-graduação, prioritariamente em programas de mestrado e doutorado".

Julga-se que simples a "preparação" não é suficiente, é preciso formação, e formação implica dar aos conteúdos pedagógicos o mesmo peso e a mesma importância 
que os conteúdos específicos da área (Biologia, por exemplo). Dessa forma, esse mesmo raciocínio deve emergir de todos os programas, projetos, políticas e ações voltados para a Educação Superior, mesmo os que são voltados apenas para os cursos de bacharelado, pois agrônomos, médicos, engenheiros, psicólogos e demais também encontram na docência na Educação Superior um espaço de trabalho importante.

\section{REFERÊNCIAS}

BALAU ROQUE, M. M. A experiência no Programa de Educação Tutorial (PET) e a formação do estudante do Ensino Superior. 2012. 119 f. Dissertação (Mestrado em Educação) - Programa de Pós-Graduação em Educação, Universidade Estadual de Campinas, Campinas, 2012.

BARDIN, L. Análise de conteúdo. Lisboa: 70, 1977.

BRASIL. Lei n. 9.394, de 20 de dezembro de 1996. Estabelece as Diretrizes e Bases da Educação Nacional. Diário Oficial [da] República Federativa do Brasil, Poder Executivo, Brasília, DF, 21 dez. 1996.

BRASIL. Lei n. 11.180, de 23 de setembro de 2005. Institui o Projeto Escola de Fábrica, autoriza a concessão de bolsas de permanência a estudantes beneficiários do Programa Universidade para Todos - Prouni, institui o Programa de Educação Tutorial - PET, altera a Lei n. 5.537, de 21 de novembro de 1968, e a Consolidação das Leis do Trabalho - CLT, aprovada pelo Decreto-Lei n. 5.452, de $1^{\circ}$ de maio de 1943, e dá outras providências. Diário Oficial [da] República Federativa do Brasil, Poder Executivo, Brasília, DF, 26 set. 2005.

BRASIL. Manual de orientações básicas. Brasília, DF: MEC, 2016.

BRASIL. Programa de Educação Tutorial. Disponível em: <http://portal.mec.gov.br/pet>. Acesso em: 8 ago. 2018.

BRASIL. Resolução n. 510, de 7 de abril de 2016. Dispõe sobre as normas aplicáveis a pesquisas em Ciências Humanas e Sociais cujos procedimentos metodológicos envolvam a utilização de dados diretamente obtidos com os participantes ou de informações identificáveis ou que possam acarretar riscos maiores do que os existentes na vida cotidiana, na forma definida nesta Resolução. Diário Oficial [da] República Federativa do Brasil, Poder Executivo, Brasília, DF, 8 abr. 2016.

CALDAS, J. B. et al. A percepção de alunos quanto ao Programa de Educação pelo Trabalho para a Saúde - PET-Saúde. Revista Brasileira de Educação Médica, Brasília, DF, v. 36, n. 1, p. 33-41, 2012. 
CÂMARA, A. M. C. S.; GROSSEMAN, S.; PINHO, D. L. M. Educação interprofissional no Programa PET-Saúde: a percepção de tutores. Interface, Botucatu, v. 19, supl. 1, p. 817829, 2015.

CASSIANI, S. H. B.; RICCI, W. Z.; SOUZA, C. R. A experiência do Programa Especial de Treinamento na educação de estudantes de graduação em Enfermagem. Revista Latino-Americana de Enfermagem, Ribeiro Preto, v. 6, n. 1, p. 63-69, 1998.

CUNHA, M. I. Formatos avaliativos e concepção de docência. Campinas: Autores Associados, 2005.

DIAS, A. M. I. Discutindo caminhos para a indissociabilidade entre ensino, pesquisa e extensão. Revista Brasileira de Docência, Ensino e Pesquisa em Educação Física, Cristalina, v. 1, p. 37-52, 2009.

DIAS, A. M. I.; FREITAS, A. L. P. Educação tutorial: do conhecimento teórico à experiência vivenciada por docentes e discentes da Universidade Federal do Ceará (UFC). Brasília, DF: MEC, 2006.

EISNER, E. E. O que a educação pode aprender das artes. Currículo sem Fronteiras, [S.I.], v. 8, n. 2, p. 5-17, 2008.

ENAPET - Encontro Nacional dos Grupos PET. Educação tutorial: ser ou não ser, eis a questão. In: ENAPET, 20., 2015, Belém. Anais... Belém: Enapet, 2015.

ENAPET - Encontro Nacional dos Grupos PET. Ensino, pesquisa, extensão: indissociabilidade. In: ENAPET, 21., 2016, Rio Branco. Anais... Rio Branco: Enapet, 2016.

ENAPET - Encontro Nacional dos Grupos PET. Inovação e formação: o desafio da construção. In: ENAPET, 19., 2014, Santa Maria. Anais... Santa Maria: UFSM, 2014.

ENAPET - Encontro Nacional dos Grupos PET. Responsabilidade social petiana: os incomodados é que mudam. In: ENAPET, 22., 2017, Brasília, DF. Resumos... Brasília, DF: Enapet, 2017.

ENAPET - Encontro Nacional dos Grupos PET. Unidos pela mesma raiz. In: ENAPET, 23., 2018, Campinas. Resultado das avaliações... Campinas: Enapet, 2018.

FARIAS-SANTOS, B. C. S.; NORO, L. R. A. PET-Saúde como indutor da formação profissional para o Sistema Único de Saúde. Ciência e Saúde Coletiva, Rio de Janeiro, v. 22, n. 3, p. 997-1004, 2017.

FAZENDA, I. Dicionário em construção: interdisciplinaridade. São Paulo: Cortez, 2001. 
FEITOSA, R. A.; LEITE, R. C. M.; FREITAS, A. L. P. "Projeto Aprendiz": interação universidade-escola para realização de atividades experimentais no Ensino Médio. Ciência \& Educação, Bauru, v. 17, n. 2, p. 301-320, 2011.

FEITOSA, R. A.; LEITE, R. C. M. A formação de professores de Ciências baseada numa Associação de Companheiros de Ofício. Revista Ensaio, Rio de Janeiro, v. 14, n. 1, p. 35-50, 2012.

FERREIRA, M. M. Produção científica na Biblioteconomia: as pesquisas realizadas no Programa de Educação Tutorial (PET) e seus reflexos na formação acadêmica. Revista Edicic, [S.I.], v. 1, n. 4, p. 99-108, 2011.

FRANCO, M. L. P. B. Análise de conteúdo. Brasília, DF: Liber, 2005.

FRIGOTTO, D.; CIAVATTA, M.; RAMOS, M. A política de educação profissional no governo Lula: um percurso histórico controvertido. Educação \& Sociedade, Campinas, v. 26, n. 92 , p. 1087-1113, 2005.

GOMES, M. F. V. B.; HAURESKO, C.; BORTOLI, C. Caminhos da/na Geografia: teoria e a prática no Programa de Educação Tutorial. In: GOMES, M. F. V. B.; HAURESKO, C.; BORTOLI, C. (Org.). Cidade, cultura e ambiente sob a perspectiva geográfica. Guarapuava: Unicentro, 2008. p. 15-32.

PETBIOUFC - PET Biologia UFC. Sobre o PET. 2015. Disponível em: <http://petbioufc.blogspot.com.br/>. Acesso em: 15 maio 2016.

PETRILLI-FILHO, J. F.; MARTINS, D. C. O PROGRAMA especial de Treinamento na formação do profissional de Enfermagem do novo milênio: relato de experiência. Revista Latino-Americana de Enfermagem, Ribeirão Preto, v. 9, n. 4, p. 91-93, 2001.

QUEIROZ, G. R. P. C. Processos de formação de professores artistas-reflexivos de Física. Educação \& Sociedade, Campinas, v. 22, n. 74, p. 97-119, 2001.

SCHÖN, D. Educando o profissional reflexivo: um novo design para o ensino e a aprendizagem. Porto Alegre: Artmed, 2000.

STAKE, R. E. The art of case study research. Thousand Oaks: Sage, 1995.

TARDIF, M.; LESSARD, C. O trabalho docente: elementos para uma teoria da docência como profissão de interações humanas. Petrópolis: Vozes, 2009.

THERRIEN, J. Professores em formação: a escola como lugar de pesquisa. In: SANTOS, F. K. S. (Org.). Professores em formação: a escola como lugar de pesquisa. Fortaleza: Seduc, 2011. p. 50-68.

UFC - Universidade Federal do Ceará. Projeto político-pedagógico do curso de graduação em Ciências Biológicas, modalidade licenciatura. Fortaleza: UFC, 2005. 
VEIGA, I. P. A. Aventura de formar professores. Campinas: Papirus, 2009.

YIN, R. K. Estudo de caso: planejamento e métodos. Porto Alegre: Bookman, 2005.

\section{Raphael Alves Feitosa (Brasil, Ceará, Fortaleza)}

Universidade Federal do Ceará (UFC)

Doutor em Educação pela UFC. Professor adjunto da UFC.

Lattes: <http://lattes.cnpq.br/1488422394078457>.

E-mail: <raphael.feitosa@ufc.br>.

\section{Ana Maria lorio Dias (Brasil, Ceará, Fortaleza)}

Universidade Federal do Ceará (UFC)

Pós-Doutora em Educação pela Universidade de Brasília (UnB). Coordenadora do Grupo de Pesquisa (CNPq) sobre formação docente da UFC. Professora permanente do Programa de Pós-Graduação em Educação da UFC e colaboradora do Programa de Pós-Graduação em Educação da Universidade Estadual do Ceará (UECE).

Lattes: <http://lattes.cnpq.br/7968107654959280>.

E-mail: <ana.iorio@yahoo.com.br>.

Recebido em 15 de janeiro de 2019.

Aceito em 11 de março de 2019. 